\title{
Analysis of the risk factors for tracheostomy and decannulation after traumatic cervical spinal cord injury in an aging population
}

\author{
Takayuki Higashi $^{1,2} \cdot$ Hideto Eguchi $^{1} \cdot$ Yusuke Wakayama $^{1} \cdot$ Masakatsu Sumi ${ }^{1} \cdot$ Tomoyuki Saito $^{1} \cdot$ Yutaka Inaba $^{1}$
}

Received: 4 January 2019 / Revised: 17 April 2019 / Accepted: 24 April 2019 / Published online: 10 May 2019

(c) International Spinal Cord Society 2019

\begin{abstract}
Study design Retrospective study.

Objectives To investigate the risk factors associated with tracheostomy after traumatic cervical spinal cord injury (CSCI) and to identify factors associated with decannulation in an aging population.

Setting Advanced critical care and emergency center in Yokohama, Japan.

Methods Sixty-five patients over 60 years with traumatic CSCI treated between January 2010 and June 2017 were enrolled. The parameters analyzed were age, sex, American Spinal Injury Association impairment scale score (AIS) at admission and one year after injury, neurological level of injury (NLI), injury mechanism, Charlson's comorbidity index (CCI), smoking history, radiological findings, intubation at arrival, treatment choice, length of intensive care unit (ICU) stay, tracheostomy rate, improvement of AIS, decannulation rate, and mortality after one year.

Results The study included 48 men (74\%; mean age $72.8 \pm 8.3$ years). Twenty-two (34\%), $10(15 \%), 24$ (37\%), and $9(14 \%)$ patients were classified as AIS A, B, C, and D, respectively. The tracheostomy group showed significantly more severe degree of paralysis, more patients with major fractures or dislocations, more operative treatment, longer ICU stay, poorer improvement in AIS score after one year and higher rate of intubation at arrival. AIS A at injury was the most significant risk factor for tracheostomy. The non-decannulation group had a significantly higher mortality. The risk factor for failure of decannulation was CCI.

Conclusions Risk factors for tracheostomy after traumatic CSCI were AIS A, operative treatment, major fracture/dislocation, and intubation at arrival. The only factor for failure of decannulation was CCI.
\end{abstract}

\section{Introduction}

Traumatic cervical spinal cord injury (CSCI) often causes severe disability and complications because of neurological deficits and respiratory dysfunction secondary to the injury. Respiratory complications are the principal cause of morbidity and mortality in CSCI patients [1].

Supplementary information The online version of this article (https:// doi.org/10.1038/s41393-019-0289-x) contains supplementary material, which is available to authorized users.

Takayuki Higashi

higashi@yokohama-cu.ac.jp

1 Department of Orthopaedic Surgery, Yokohama City University School of Medicine, Yokohama, Japan

2 Present address: Yokohama City University Medical Center, 4-57 Urafunecho, Minami-ku, Yokohama 232-0024, Japan
Respiratory dysfunction from CSCI is due to the disruption of innervation to the diaphragm and intercostal muscles, resulting in the need for long-term mechanical ventilation. Because mechanical ventilation is associated with increased risk of respiratory complications, early tracheostomy is recommended to reduce complications and improve outcomes [2,3].

Previous studies have suggested that tracheostomy is required in patients with severe traumatic CSCI $[4,5]$ and early tracheostomy in traumatic CSCI patients improves respiratory outcomes [2]. Delayed tracheostomy has been associated with increased duration of hospital stay, increased duration of treatment in the intensive care unit, infectious complications, and delays in initiating acute rehabilitation [5]. Nevertheless, studies have reported that unnecessary tracheostomy has detrimental effects [6] and avoiding empiric use of tracheostomy decreases numerous tracheostomy-related complications and respiratory morbidities [7]. 
The purpose of tracheostomy for CSCI patients is airway control. If possible, all tracheostomies should be closed as soon as the condition of the patient allows, but some patients cannot tolerate decannulation. The invasiveness of tracheostomy is both physical and psychological [8, 9]; hence, the effort for avoiding unnecessary tracheostomy and that for decannulation are particularly important in traumatic CSCI patients. There has been one study regarding indications for decannulation; however, the CSCI patients in that study was relatively young [9]. The incidence of traumatic CSCI in the elderly population is rising [10-13], and the mortality due to traumatic spinal cord injury in the elderly patients is higher than that in the young patients $[11,14]$. No previous studies have reported the risk factors for failure of decannulation in aging traumatic CSCI patients.

The purpose of the current study was to investigate the factors associated with tracheostomy and decannulation in traumatic CSCI at an advanced critical care and emergency center in Japan and to identify the risk factors for tracheostomy and failure of decannulation in an aging population.

\section{Methods}

This study was approved by the ethics research board of the Yokohama City University School of Medicine. All patients provided informed consent for the use of their data in the study. A total of 89 traumatic cervical spinal cord injury patients were treated at our institution between January 2010 and June 2017. Our exclusion criteria were (a) age under 60 years and (b) severe head injury. After application of these criteria, 65 patients entered into the study (Supplementary file 1). We analyzed the medical records of patients visiting our outpatient department during the study period, and the follow-up of patients who had been transferred to another hospital was based on the patient report sent to us by the receiving hospital. Patients included 48 males (74\%) and 17 females (26\%) ranging from 60 to 94 years with a mean age of $72.8 \pm 8.3$ years. The following data were analyzed: age, gender, the American Spinal Injury Association impairment scale (AIS) [15] at admission and one year after injury, neurological level of injury (NLI), injury mechanism, Charlson comorbidity index (CCI) [16] as an evaluation of preexisting comorbidity (PEC), smoking history, radiological findings (i.e., with or without major fracture or dislocation), intubation at arrival, choice of treatment, ICU length of stay, tracheostomy, decannulation, and mortality after one year. CSCI patients with a major fracture or dislocation were received surgical treatment, and in the patients without a major fracture or dislocation, conservative treatment was selected unless the patients want to receive surgical treatment. Mortality included in-hospital death and death within one year. If the AIS improved one year after admission, it was defined as improvement. To examine associated factors for tracheostomy in CSCI, all patients were categorized into two groups: patients who did or did not undergo tracheostomy. To examine associated factors for decannulation in CSCI, the patients who underwent tracheostomy were categorized into two groups: decannulation or non-decannulation.

Data are presented as the mean value \pm standard deviation. A chi-square test and unpaired $t$-test were used to examine differences in the outcome measurements between the groups. A $p$-value of $<0.05$ was considered statistically significant. A univariate logistic regression model was used to assess the risk factors for tracheostomy and failure of decannulation, and a multivariate logistic regression model was used to analyze significant risk factors for tracheostomy using the factors which were statistically significant in the univariate logistic regression. Age was assessed as a continuous variable. Gender, AIS, NLI, radiological findings, CCI, smoking history, choice of treatment, intubation at arrival were dichotomized as male or not, an AIS A or not, a NLI C4 or above or not, major fracture or dislocation or not, a CCI two or more or not, smoking history or not, operation or not, intubation at arrival or not. All statistical analyses were performed using the $\mathrm{JMP}^{\circledR}$ pro 12 (SAS Institute Inc., Cary, NC, USA).

\section{Results}

Table 1 presents the characteristics of the traumatic CSCI patient cohort. Twenty-two (34\%), 10 (15\%), 24 (37\%), and 9 (14\%) patients were classified as AIS A, B, C, and D, respectively. The neurological level of injury was distributed from $\mathrm{C} 2$ to $\mathrm{T} 1$, with the majority occurring at the levels C4 (26\%) and C5 (40\%). There were relatively fewer injuries occurring at the levels C2 (3\%), C3 (6\%), C6 (8\%), C7 (11\%), C8 (3\%), and T1 (3\%). Falls from standing (35\%) and heights (42\%) were common causes of injury, followed by traffic accidents $(22 \%)$. Twenty-seven patients (42\%) were classified as having CCI 0, 20 (31\%) as having CCI 1 , and $18(28 \%)$ as having CCI 2 or more. Thirty-six patients $(57 \%)$ had a smoking history. Intubation at arrival was performed in 9 patients (14\%). Forty-six patients $(71 \%)$ had CSCI without major fracture or dislocation. Among the entire cohort, 35 patients $(54 \%)$ had undergone surgery and $30(46 \%)$ had received conservative treatment. A tracheostomy was performed on 20 patients $(31 \%)$. Of these patients, $6(9 \%)$ had a successful decannulation. The mean length of ICU stay was $9.3 \pm 11.6$ days. The mortality at one year from injury was $14 \%$. 
Table 1 Patient characteristics

\begin{tabular}{|c|c|}
\hline Age (years) & $72.8 \pm 8.3$ \\
\hline Gender (M:F) & $48: 17$ \\
\hline \multicolumn{2}{|l|}{$A I S$} \\
\hline A & $22(34 \%)$ \\
\hline B & $10(15 \%)$ \\
\hline $\mathrm{C}$ & $24(37 \%)$ \\
\hline $\mathrm{D}$ & $9(14 \%)$ \\
\hline \multicolumn{2}{|l|}{$N L I$} \\
\hline $\mathrm{C} 2$ & $2(3 \%)$ \\
\hline $\mathrm{C} 3$ & $4(6 \%)$ \\
\hline $\mathrm{C} 4$ & $17(26 \%)$ \\
\hline C5 & $26(40 \%)$ \\
\hline C6 & $5(8 \%)$ \\
\hline $\mathrm{C} 7$ & $7(11 \%)$ \\
\hline $\mathrm{C} 8$ & $2(3 \%)$ \\
\hline $\mathrm{T} 1$ & $2(3 \%)$ \\
\hline \multicolumn{2}{|l|}{ Injury mechanism } \\
\hline Fall from standing & $23(35 \%)$ \\
\hline Fall from height & $27(42 \%)$ \\
\hline Traffic accident & $14(22 \%)$ \\
\hline Other & $1(2 \%)$ \\
\hline \multicolumn{2}{|l|}{ Radiological finding } \\
\hline Major fracture or dislocation & $19(29 \%)$ \\
\hline No major fracture or dislocation & $46(71 \%)$ \\
\hline \multicolumn{2}{|l|}{$C C I$} \\
\hline 0 & $27(42 \%)$ \\
\hline 1 & $20(31 \%)$ \\
\hline$\geqq 2$ & $18(28 \%)$ \\
\hline Smoking history & $36(55 \%)$ \\
\hline \multicolumn{2}{|l|}{ Treatment } \\
\hline Operation & $35(54 \%)$ \\
\hline Conservative & $30(46 \%)$ \\
\hline ICU length of stay (day) & $9.3 \pm 11.6$ \\
\hline Tracheostomy & $20(31 \%)$ \\
\hline Decannulation & $6(9 \%)$ \\
\hline Mortality & $14(22 \%)$ \\
\hline \multicolumn{2}{|l|}{ AIS after one year } \\
\hline A & $11(17 \%)$ \\
\hline B & $0(0 \%)$ \\
\hline $\mathrm{C}$ & $15(23 \%)$ \\
\hline $\mathrm{D}$ & $18(28 \%)$ \\
\hline $\mathrm{E}$ & $7(11 \%)$ \\
\hline Intubation at arrival & $9(14 \%)$ \\
\hline
\end{tabular}

AIS American Spinal Injury Association impairment scale, NLI neurological level of injury, CCI Charlson comorbidity index

The comparison of patients who underwent tracheostomy and those who did not is summarized in Table 2. At injury, the AIS was significantly different between the groups. The
Table 2 Comparison between patients with and without tracheostomy

\begin{tabular}{|c|c|c|c|}
\hline & Tracheostomy & No tracheostomy & $p$ value \\
\hline Number of patients & 20 & 45 & \\
\hline Age (year) & $73.2 \pm 7.4$ & $63.8 \pm 8.7$ & 0.80 \\
\hline Gender & & & 0.64 \\
\hline Male & $16(80 \%)$ & $32(71 \%)$ & \\
\hline Female & $4(20 \%)$ & $13(29 \%)$ & \\
\hline AIS & & & $<0.0001$ \\
\hline A & $15(75 \%)$ & $7(16 \%)$ & \\
\hline B & $2(10 \%)$ & $8(18 \%)$ & \\
\hline $\mathrm{C}$ & $3(15 \%)$ & $21(47 \%)$ & \\
\hline $\mathrm{D}$ & $0(0 \%)$ & $9(20 \%)$ & \\
\hline$N L I$ & & & 0.29 \\
\hline $\mathrm{C} 2$ & $2(10 \%)$ & $0(0 \%)$ & \\
\hline $\mathrm{C} 3$ & $0(0 \%)$ & $4(9 \%)$ & \\
\hline $\mathrm{C} 4$ & $5(25 \%)$ & $12(27 \%)$ & \\
\hline C5 & $9(45 \%)$ & $17(38 \%)$ & \\
\hline C6 & $2(10 \%)$ & $3(7 \%)$ & \\
\hline C7 & $2(10 \%)$ & $5(11 \%)$ & \\
\hline $\mathrm{C} 8$ & $0(0 \%)$ & $2(4 \%)$ & \\
\hline $\mathrm{T} 1$ & $0(0 \%)$ & $2(4 \%)$ & \\
\hline Injury mechanism & & & 0.053 \\
\hline Fall from standing & $3(15 \%)$ & $20(44 \%)$ & \\
\hline Fall from height & $13(65 \%)$ & $14(31 \%)$ & \\
\hline Traffic accident & $4(20 \%)$ & $10(22 \%)$ & \\
\hline Other & $0(0 \%)$ & $1(2 \%)$ & \\
\hline Radiological finding & & & 0.01 \\
\hline $\begin{array}{l}\text { Major fracture or } \\
\text { dislocation }\end{array}$ & $10(50 \%)$ & $9(20 \%)$ & \\
\hline $\begin{array}{l}\text { No major fracture or } \\
\text { dislocation }\end{array}$ & $10(50 \%)$ & $36(80 \%)$ & \\
\hline$C C I$ & & & 0.88 \\
\hline 0 & $8(40 \%)$ & $19(42 \%)$ & \\
\hline 1 & $7(35 \%)$ & $13(29 \%)$ & \\
\hline$\geqq 2$ & $5(25 \%)$ & $13(29 \%)$ & \\
\hline Smoking history & $12(60 \%)$ & $24(53 \%)$ & 0.62 \\
\hline Treatment & & & 0.002 \\
\hline Operation & $15(75 \%)$ & $20(44 \%)$ & \\
\hline Conservative & $5(25 \%)$ & $25(56 \%)$ & \\
\hline ICU length of stay (day) & $21.6 \pm 13.7$ & $3.8 \pm 3.9$ & $<0.0001$ \\
\hline Mortality & $7(35 \%)$ & $7(16 \%)$ & 0.08 \\
\hline AIS after one year & & & $<0.0001$ \\
\hline A & $8(40 \%)$ & $3(7 \%)$ & \\
\hline B & $0(0 \%)$ & $0(0 \%)$ & \\
\hline $\mathrm{C}$ & $5(25 \%)$ & $10(22 \%)$ & \\
\hline $\mathrm{D}$ & $5(25 \%)$ & $18(40 \%)$ & \\
\hline E & $0(0 \%)$ & $7(16 \%)$ & \\
\hline Improvement of AIS & $3(15 \%)$ & $25(56 \%)$ & 0.002 \\
\hline Intubation at arrival & $6(30 \%)$ & $3(7 \%)$ & 0.02 \\
\hline
\end{tabular}

AIS American Spinal Injury Association impairment scale, NLI neurological level of injury, $C C I$ Charlson comorbidity index

degree of paralysis was significantly more severe in patients who underwent tracheostomy than that in those who did not. There was an equivalent difference in the AIS after one year in both groups. The length of ICU stay was significantly longer in the tracheostomy group than that in the non-tracheostomy group. The number of patients with 
Table 3 Logistic regression analysis for the necessity of tracheostomy

\begin{tabular}{|c|c|c|c|c|}
\hline & \multicolumn{2}{|l|}{ Univariate } & \multicolumn{2}{|l|}{ Multivariate } \\
\hline & OR $(95 \% \mathrm{CI})$ & $p$ value & OR $(95 \% \mathrm{CI})$ & $p$ value \\
\hline Age (year) & $0.99(0.9-1.1)$ & 0.79 & & \\
\hline Gender & $1.6(0.5-6.5)$ & 0.44 & & \\
\hline AIS A & $12.7(3.8-47.9)$ & $<0.0001$ & $11.2(3.0-49.7)$ & 0.0003 \\
\hline $\mathrm{NLI} \geqq \mathrm{C} 4$ & $0.97(0.3-2.9)$ & 0.97 & & \\
\hline Major fracture or dislocation & $4.0(1.3-12.9)$ & 0.02 & $1.9(0.4-10.1)$ & 0.45 \\
\hline $\mathrm{CCI} \geqq 2$ & $0.8(0.2-2.6)$ & 0.74 & & \\
\hline Smoking history & $1.3(0.5-3.9)$ & 0.61 & & \\
\hline Operation & $3.8(1.2-13.2)$ & 0.02 & $2.8(0.5-16.2)$ & 0.23 \\
\hline Intubation at arrival & $6.0(1.4-31.5)$ & 0.02 & $2.7(0.4-19.3)$ & 0.29 \\
\hline
\end{tabular}

$O R$ odds ratio, $C I$ confidence interval, AIS American Spinal Injury Association impairment scale, NLI neurological level of injury, $C C I$ Charlson comorbidity index major fractures or dislocations was significantly higher in the tracheostomy group. There were significantly more patients who underwent operative treatment in the tracheostomy group. The AIS improvement was significantly poorer in the tracheostomy group than that in the nontracheostomy group. Intubation at arrival was significantly higher in the tracheostomy group. The age, gender, neurological level of injury, injury mechanism, CCI, smoking history, and mortality did not differ significantly between the groups.

A univariate logistic regression model (Table 3) indicated that AIS A, major fracture or dislocation, operative treatment, and intubation at arrival were significant risk factors for tracheostomy. In the multivariate logistic regression model, AIS A at injury was a significant risk factor for tracheostomy.

The comparison of patients who underwent successful decannulation and those who did not is summarized in Table 4. Mortality was higher in the non-decannulation group. No patient recovered from paralysis within one year in the non-decannulation group.

A univariate logistic regression model indicated that CCI was a significant risk factor for decannulation failure ( $p$-value $=0.04$, odds ratio: $4.4,95 \%$ CI 1.04-34.2), and other factors that was age, gender, AIS, NLI, major fracture or dislocation, smoking, operative treatment, tracheostomy timing, and intubation at arrival were not significant risk factors for decannulation failure (Supplementary Table 1).

\section{Discussion}

Respiratory failure is the most frequent complication of traumatic CSCI [1, 17]. Tracheostomy is an important supportive therapy for traumatic CSCI patients, because it can improve ventilatory function and treatment efficacy $[2,3,18,19]$. Nevertheless, a few studies have reported that unnecessary tracheostomy or the empiric use of tracheostomy should be avoided because of the numerous tracheostomy-related complications and respiratory morbidities [6, 7]. Shao et al. [20] demonstrated that early mortality is significantly higher in patients who underwent tracheostomy because it breaches the natural barrier between the lung and the external environment, significantly increasing the probability of infection.

Numerous studies have reported risk factors associated with tracheostomy in CSCI patients [4, 5, 21, 22], and there is a meta-analysis of the influencing factors for tracheostomy after CSCI [22]. According to that meta-analysis, the current evidence shows that male gender, AIS A or B, upper neurological level of injury, high ISS, GCS $\leqq 8$, thoracic injury, and respiratory complications are risk factors for tracheostomy after traumatic CSCI. Age, smoking history, and mechanism of injury were not risk factors for tracheostomy [22]. In the present study, the univariate logistic regression analysis showed that the risk factors for tracheostomy were severe AIS, major fracture or dislocation, operative treatment, and intubation at arrival. The reason may be that patients with major fractures or dislocations usually require operative treatment, resulting in prolonged ICU stays, and a more severe AIS is associated with a greater need for mechanical ventilation [18]. Although tracheostomy was associated with lower ICU length of stay in a previous study [2], it was longer in the tracheostomy group in the present study. The reason is that the present study included elderly patients who had low energy injury and no severe paralysis and many of them did not need to receive long ICU treatment and tracheostomy. The multivariate logistic regression analysis shows that a significant risk factor for tracheostomy was the severity of the AIS at injury.

The CSCI in older patients is associated with increased frequency of complications, higher mortality and poorer prognosis than in younger patients [23]. Fassett et al. [10] 
Table 4 Comparison between patients with and without decannulation

\begin{tabular}{|c|c|c|c|}
\hline & Decannulation & No decannulation & $p$ value \\
\hline Number of patients & 6 & 14 & \\
\hline Age (year) & $75.2 \pm 4.0$ & $72.4 \pm 8.5$ & 0.81 \\
\hline Gender & & & 0.81 \\
\hline Male & 5 & 11 & \\
\hline Female & 1 & 3 & \\
\hline$A I S$ & & & 0.79 \\
\hline A & 4 & 11 & \\
\hline B & 1 & 1 & \\
\hline $\mathrm{C}$ & 1 & 2 & \\
\hline $\mathrm{D}$ & 0 & 0 & \\
\hline$N L I$ & & & 0.14 \\
\hline $\mathrm{C} 2$ & 0 & 2 & \\
\hline $\mathrm{C} 3$ & 0 & 0 & \\
\hline $\mathrm{C} 4$ & 2 & 3 & \\
\hline $\mathrm{C} 5$ & 2 & 7 & \\
\hline C6 & 0 & 2 & \\
\hline $\mathrm{C} 7$ & 2 & 0 & \\
\hline Injury mechanism & & & 0.58 \\
\hline Fall from standing & 1 & 2 & \\
\hline Fall from height & 3 & 10 & \\
\hline Traffic accident & 2 & 2 & \\
\hline Radiological finding & & & 0.33 \\
\hline $\begin{array}{l}\text { Major fracture or } \\
\text { dislocation }\end{array}$ & 4 & 6 & \\
\hline $\begin{array}{l}\text { No major fracture or } \\
\text { dislocation }\end{array}$ & 2 & 8 & \\
\hline$C C I$ & & & 0.06 \\
\hline 0 & 4 & 4 & \\
\hline 1 & 2 & 5 & \\
\hline$\geqq 2$ & 0 & 5 & \\
\hline Smoking history & 2 & 10 & 0.11 \\
\hline Treatment & & & 0.57 \\
\hline Operation & 5 & 10 & \\
\hline Conservative & 1 & 4 & \\
\hline ICU length of stay (day) & $17.0 \pm 13.0$ & $23.6 \pm 14.0$ & 0.34 \\
\hline Mortality & 0 & 7 & 0.03 \\
\hline AIS after one year & & & 0.053 \\
\hline A & 2 & 6 & \\
\hline B & 0 & 0 & \\
\hline $\mathrm{C}$ & 4 & 1 & \\
\hline $\mathrm{D}$ & 0 & 0 & \\
\hline $\begin{array}{l}\text { Tracheostomy } \\
\text { timing (day) }\end{array}$ & $6.2 \pm 2.6$ & $7.0 \pm 5.3$ & 0.72 \\
\hline Improvement of AIS & 3 & 0 & 0.004 \\
\hline Intubation at arrival & 3 & 3 & 0.20 \\
\hline
\end{tabular}

AIS American Spinal Injury Association impairment scale, NLI neurological level of injury, $C C I$ Charlson comorbidity index reported that geriatric patients were vulnerable to traumatic SCI and the mortality rate in geriatric patient group was much greater than in younger patients. Harrop et al. [5] reported that patient age was significantly associated with tracheostomy. Although there have been few reports for tracheostomy in the older patients [24], as far as the authors know, there have been no reports published on tracheostomy and decannulation after traumatic CSCI in the older patients.

In the present study, NLI was not the risk factor for tracheostomy. There have been many reports of NLI as a risk factor for tracheostomy after traumatic CSCI [2, 18, 21]. Flanagan et al. [2] reported that higher neurological level of injury was predictive factor of early tracheostomy. On the other hand, Childs et al. [18] reported that the level of injury did not predict the need for tracheostomy. this study indicated that in an aging population, the severity of paralysis was a significant risk factor of tracheostomy and neurological level of paralysis was not a significant risk factor.

In the present study, the need for early intubation was associated with tracheostomy and risk factor for tracheostomy, and this was not associated with decannulation. Como et al. [25] reported that almost all patients in high complete CSCI group required a very early definitive airway because of their initial injury, and early intubation and tracheostomy were recommended for patients with complete CSCI, especially for those with NLI of C5 and above. Early intubation suggests severe respiratory failure and correlates with tracheostomy.

There have been few reports of tracheostomy patients after CSCI who underwent successful decannulation. Nakashima et al. [9] reported that 21/25 (84\%) CSCI patients underwent successful decannulation. In their report, high cervical level complete SCI was a risk factor for the failure of decannulation in patients without shoulder shrug within 3 weeks after injury. On the other hand, in the present study, there were 6 patients $(30 \%)$ who had undergone successful decannulation after traumatic CSCI within one year. The reason for the difference in successful decannulation rate may be the difference in the ages of the populations. The mean age of the patients in the study by Nakashima et al. [9] was 44.2 years, younger than that of the patients in the present study (72.8 years). Furthermore, the patients in the study by Nakashima et al. [9] all underwent surgery, meaning that there were few patients without major fractures or dislocations in the study. The majority of patients without major fractures or dislocations are in the elderly population, and surgical treatment might not be recommended for traumatic CSCI without major fractures or dislocations [26]. Kim et al. [7] reported that 
almost all 60 tracheostomy patients with complete or sensory incomplete CSCI underwent successful decannulation. The differences in the present study are the mean age of patients (47.6 vs. 72.8) and the use of noninvasive mechanical ventilation after decannulation in a pulmonary rehabilitation center.

To the best of our knowledge, the present study is the first report of decannulation after traumatic CSCI in an aging population. Recently, the incidence of traumatic CSCI in the elderly is increasing [10-13], so the present study reflects the recent aging population in Japan and other countries.

Elderly tracheostomy patients differ from younger tracheostomy patients with regard to physical ability [24]. Hayashi et al. [27] reported that old age, severe paralysis and tracheostomy might be risk factors for dysphagia. The risk of dysphagia is associated with aspiration pneumonia. Additionally, Shao et al. [20] reported that the risk of early mortality was significantly higher in patients who underwent tracheotomy than in those who did not undergo tracheotomy, and age was a significant risk factor for early mortality. Old age is associated with poor prognosis in CSCI patients who need tracheostomy. A higher frequency of PEC in elderly patients than in younger patients is one of the reasons for poor prognosis.

In the present study, the successful decannulation rate was $30 \%$, and the mortality of the remaining patients who failed decannulation was 35\%. Risk factor for the failure of decannulation was CCI. The previous studies have reported that PEC was the predictor of mortality in elderly CSCI patients [28, 29]. Many of elderly patients have some sort of PEC, and Harris et al. [30] demonstrated that the number of comorbid illness is the most important predictor of mortality in elderly CSCI patients. In the present study, CCI was a risk factor for the failure of decannulation after traumatic CSCI in an aging population, and this result was not inconsistent with the previous studies.

The present study has several limitations. One is that it was a retrospective study that included a relatively small sample in over a seven-year period. Second, it was conducted at a single center in an advanced critical care and emergency center. Third, definite eligibility criteria for a tracheostomy have yet to be formulated at this center.

In an aging population, the risk factors for tracheostomy after traumatic CSCI were severity of the AIS, operative treatment, major fracture or dislocation, and intubation at arrival. The risk factor associated with failure of decannulation was CCI.

\section{Data archiving}

All data generated or analyzed during this study are included in this published article and a supplementary file.
Acknowledgements We are grateful to Editage for the English language review.

Author contributions TH, HE, YW, and MS were responsible for study conception and design, acquisition of data, statistics, analysis and interpretation of data, and drafting of manuscript. TS and YI were involved in analysis and interpretation of data, and drafting of manuscript.

\section{Compliance with ethical standards}

Ethical approval This study was approved by the ethics research board of the Yokohama City University School of Medicine. The reference number is B17080001. We certify that all applicable institutional and governmental regulations concerning the ethical use of human volunteers were followed during the course of this research.

Conflict of interest The authors declare that they have no conflict of interest.

Publisher's note: Springer Nature remains neutral with regard to jurisdictional claims in published maps and institutional affiliations.

\section{References}

1. Brown R, DiMarco AF, Hoit JD, Garshick E. Respiratory dysfunction and management in spinal cord injury. Respir Care. 2006;51:853-70.

2. Flanagan CD, Childs BR, Moore TA, Vallier HA. Early tracheostomy in patients with traumatic cervical spinal cord injury appears safe and may improve outcomes. Spine. 2018;43:1110-6.

3. Ganuza JR, Forcada AG, Gambarrutta C, Buigues ED, Gonzalez VE, Fuentes FP, et al. Effect of technique and timing of tracheostomy in patients with acute traumatic spinal cord injury undergoing mechanical ventilation. J Spin Cord Med. 2011; 34:76-80.

4. Beom JY, Seo HY. The need for early tracheostomy in patients with traumatic cervical cord injury. Clin Orthop Surg. 2018;10:191-6.

5. Harrop JS, Sharan AD, Scheid JrEH, Vaccaro AR, Przybylski GJ. Tracheostomy placement in patients with complete cervical spinal cord injuries: American Spinal Injury Association grade A. J Neurosurg Spine. 2004;100:20-23.

6. Yugue I, Okada S, Ueda T, Maeda T, Mori E, Kawano O. Analysis of the risk factors for tracheostomy in traumatic cervical spinal cord injury. Spine. 2012;37:E1633-8.

7. Kim DH, Kang SW, Choi WA, Oh HJ. Successful tracheostomy decannulation after complete or sensory incomplete cervical spina cord injury. Spinal Cord. 2017;55:601-5.

8. Gilony D, Gilboa D, Blumstein T, Murad H, Talmi YP, Kronenberg $\mathrm{J}$, et al. Effects of tracheostomy on well-being and body-image perceptions. Otolaryngol Head Neck Surg. 2005;133:366-71.

9. Nakashima H, Yukawa Y, Imagama S, Ito K, Hida T, Machino M, et al. Characterizing the need for tracheostomy placement and decannulation after cervical spinal cord injury. Eur Spine J. 2013;22:1526-32.

10. Fasset DR, Harrop JS, Maltenfort M, Jeyamohan SB, Ratliff JD, Anderson DG, et al. Mortality rates in geriatric patients with spinal cord injuries. J Neurosurg Spine. 2007;7:277-81.

11. Hagen EM, Aarli JA, Gronning M. The clinical significance of spinal cord injuries in patients older than 60 years of age. Acta Neurol Scand. 2005;112:42-47.

12. Pickett GE, Campos-Benitez M, Keller JL, Duggal N. Epidemiology of traumatic spinal cord injury in Canada. Spine. 2006; 31:799-805. 
13. Sakai H, Ueda T, Shiba K. Current situation of medical care for spinal cord injury in Japan. J Spine Res. 2010;1:41-51.

14. Lidal IB, Snekkevik H, Aamodt G, Hjeltnes N, Stanghelle JK, Biering-Sørensen F. Mortality after spinal cord injury in Norway. J Rehabil Med. 2007;39:145-51.

15. Maynard FM Jr, Bracken MB, Creasey GJ, Ditunno JF, Donovan $\mathrm{WH}$, et al. International standards for neurological and functional classification of spinal cord injury. Spinal Cord. 1997;35:266-74.

16. Charlson ME, Pompei P, Ales KL, MacKenzie CR. A new method of classifying prognostic comorbidity in longitudinal studies: development and validation. J Chron Dis. 1987;40: 373-83.

17. Reins DH, Harris RC. Pulmonary complications of acute spinal cord injuries. Neurosurgery. 1987;21:193-6.

18. Childs BR, Moore TA, Como JJ, Vallier HA. American spinal injury association impairment scale predicts the need for tracheostomy after cervical spinal cord injury. Spine. 2015;40:1407-13.

19. Romero J, Vari A, Ganbarrutta C, Oliviero A. Tracheostomy timing in traumatic spinal cord injury. Eur Spine J. 2009; 18:1452-7.

20. Shao J, Zhu W, Chen X, Jia L, Song D, Zhou X, et al. Factors associated with early mortality after cervical spinal cord injury. J Spinal Cord Med. 2011;34:555-62.

21. Tanaka J, Yugue I, Shiba K, Maeyama A, Naito M. A study of risk factors for tracheostomy in patients with a cervical spinal cord injury. Spine. 2016;41:764-71.

22. Wang Y, Guo Z, Fan D, Lu H, Xie D, Zhang D, et al. A metaanalysis of the influencing factors for tracheostomy after cervical spinal cord injury. Biomed Res Int. 2018; [Epub ahead of print] https://doi.org/10.1155/2018/5895830.

23. DeVivo MJ, Kartus PL, Rutt RD, Stover SL, Fine PR. The influence of age at time of spinal cord injury on rehabilitation outcome. Arch Neurol. 1990;47:687-91.

24. Engoren MC, Arslanian-Engoren CM. Outcome after tracheostomy for respiratory failure in the elderly. J Intensive Care Med. 2005;20:104-10.

25. Como JJ, Sutton ER, McCunn M, Dutton RP, Johnson SB, Aarabi $\mathrm{B}$, et al. Characterizing the need for mechanical ventilation following cervical spinal cord injury with neurologic deficit. J Trauma. 2005;59:912-6.

26. Takao T, Okada S, Morishita Y, Maeda T, Kubota K, Ideta R, et al. Clinical influence of cervical spinal canal stenosis on neurological outcome after traumatic cervical spinal cord injury without major fracture or dislocation. Asian Spine J. 2016; 10:536-42.

27. Hayashi T, Fujiwara Y, Sakai H, Maeda T, Ueta T, Shiba K. Risk factors for severe dysphagia in acute cervical spinal cord injury. Spinal Cord. 2017;55:940-3.

28. Xing D, Wang J, Song D, Xu W, Chen Y, Yang Y, et al. Predictors for mortality in elderly patients with cervical spine injury: a systematic methodological review. Spine. 2013;38:770-7.

29. Alsaleh K, Bednar D, Farrokhyar F. Acute traumatic quadriplegia in adults: predictors of acute in-hospital mortality. Turk Neurosurg. 2017;27:942-5.

30. Harris MB, Reichmann WM, Bono CM, Bouchard K, Corbett KL, Warholic N, et al. Mortality in elderly patients after cervical spine fractures. J Bone Jt Surg Am. 2010;92:567-74. 